\title{
Comparison of the effect of two methods of acupressure and ice massage on the Hugo point on the severity of pain after appendectomy surgery
}

\author{
Research Article
}

\section{Sedighe Khalili-Shomia ${ }^{1}$, Mostafa Nasiri ${ }^{2}$, Somaye Sadeghi Nasab ${ }^{3,4}$, Arezoo Davarinia Motlagh Quchan ${ }^{4,5^{*}}$}

1. Lecturer, Faculty Member of Paramedicine School, MSc in Medical-Surgical Nursing, Student Research Committee, Sabzevar University of Medical Sciences, Sabzevar, Iran

2. Computer engineering, Tamin Ejtemai Amol, Mazandaran, Iran

3. BSC in surgical technologist, Torbat-e-Jam University, Torbat-e-Jam, Iran

4. Student Research Committee, Sabzevar University of Medical Sciences, Sabzevar, Iran

5. Lecturer. MSc in Critical Care Nursing, Faculty Member of Paramedicine School,

Sabzevar University of Medical Sciences, Sabzevar, Iran

\begin{abstract}
Introduction and aim: Pain is a distressing symptom of patients undergoing surgery. Therefore, it is essential to achieve non-invasive methods in order to relieve postoperative pain. The aim of the present study was to compare of the effect of two methods, acupressure and ice massage on the Hugo point on the severity of pain after appendectomy surgery. Methods: The present one-blind clinical trial study was conducted on 90 patients undergoing appendectomy. Samples were selected using available sampling method and then randomly divided into three groups of acupressure, ice massage and control. All three groups received routine treatment. The severity of pain was measured and compared with the standard visual standard of pain before, immediately after and one hour after intervention in all three groups. Data was analyzed using SPSS 21. Findings: The severity of pain before intervention in all three groups did not have a significant relationship with each other, while the intensity of pain immediately after and one hour after the intervention had a significant relationship. Both acupressure and ice massage helped relieve pain after appendectomy, but the effect of ice massage was higher. There was no significant difference before and after the intervention in the acupressure group. Conclusion: Considering the positive effects of Hugo point ice massage on relieving pain after appendectomy and considering the non-invasive nature, this method is considered as a valuable technique for relieving postoperative pain in patients; therefore, it is highly recommended after appendectomy surgery.
\end{abstract}

Keywords: Acupressure, Ice Massage, Hugo, Appendectomy.

\section{Introduction}

Every year, more than hundreds of millions of people are undergoing surgery (1). Acute appendicitis is the most common cause of acute abdominal pain and surgery, with $7 \%$ of people requiring appendectomy due to acute appendicitis in their lifetime. The incidence of appendicitis in the United States has increased from 7.26 to 9.38 per 10000 between 1993 and 2008, and the ratio of males to females is 1.3 to 1 . The maximum prevalence is in the male population between the ages of 15 and 25 and the risk of appendectomy is 6.8 percent during the life of a man and 6.7 during a woman's life (2). If appendectomy is not performed as soon as possible in patients with acute appendicitis, the appendix's wall tissue will get blackened and ruptured, which can have dangerous consequences, such as sepsis and even death (3).

Surgery and anesthesia cause some physiological impairment. The body's response to stress and surgical injury include the secretion of cortisol, catecholamine,

*Corresponding Author:

Arezoo Davarinia Motlagh Quchan

Student Research Committee,

Sabzevar University of Medical Sciences,

Sabzevar, Iran.

Email: a.davarinia@yahoo.com cytokinesis, ADH, and glucagon. Some of the metabolic responses and body responses to the surgery result in the imbalance of important physiological functions, resulting in complications after anesthesia and surgery including pain, changes in body temperature, restlessness, delusions, nausea and vomiting, etc. (4). Studies show that $30 \%$ of patients undergo mild pain, $30 \%$ moderate pain and $40 \%$ experience severe pain (5). In general, surgery and postoperative pain cause changes in the respiratory system, so that a painful surgical cut leads to increased reflex tone in the muscles of the tail and exhale and decreases the diaphragm function, resulting in decreased pulmonary capacity and inability in deep breathing or effective cough; even, in some cases hypoxia, hypercapnia, retention of discharge, atelectasis, and pneumonia might appear. Other complications of postoperative pain include increased blood pressure and heart rate, myocardial ischemia or heart rhythmic disorders, endocrine disorders, ileus, nausea and vomiting, increased venous thrombosis and, in addition, anxiety and discomfort (6). Drugs and non-steroidal anti-inflammatory drugs are the most common treatment for postoperative pain (7). Opiates weaken the respiratory system and generate nausea, vomiting, constipation, and loss of intellectual processes (8). Medications used to control the pain of the patient have many side effects on the body and the 
psyche of the patients (9). In addition to the risk of addiction and drug dependence, the analgesics reduce blood pressure, weaken vital functions and generate drowsiness, nausea, vomiting and even shock. It also imposes a high cost on the health system, so the need to use non-prescriptive methods to control pain in patients is fully justified (9). Currently, people's desire to use alternative therapies is growing rapidly. A study in Iran also showed that about $80 \%$ of patients wanted doctors to provide complementary therapies for them (10). In Chinese medicine, several alternative methods have been used to relieve pain. Acupuncture, acupressure and herbal fragrances are some common ones. Acupressure function is the same as acupuncture but without the use of a needle that balances energy through a number of channels called meridians that flow in the body and into certain organs in the body (11). Acupressure is a method that is done easily by a nurse (12). There are various points in the hands and fingers that have the best effect in relieving pain and generating relaxation (11). Hugo point, which is the focus of the present study, is the center of the angle between the bones of the first and second fingers of the hand between the thumb and the pointer on the back of the hand. The position of this point is where the energy flow is closer to the skin surface, which can be easily stimulated by pressure, needle or extreme cold (13). Several studies have shown different effects of acupressure, of which the effects of acupressure on dysmenorrhea, neck pain, pain due to fracture of the wrist are some of the most commonly quoted ones (14).

Also, evidence suggests that acupuncture and Hugo point ice massage have facilitated relieving pain in various cases. In Chang and Hang's study, results showed that acupressure at the Hugo point can relieve pain immediately, half and an hour after intervention. Sultanpour et al. study, also, used Hugo Point massage to relieve the pain caused by needle insertion into the artery venous fistula in hemodialysis patients

(13). Given that acupressure and ice massage are simple and inexpensive methods and also the limited number of studies conducted in this area, the present study was conducted to compare the effect of acupressure and ice massage on postoperative appendectomy pain in order to relieve postoperative pain.

\section{Materials and Methods}

This study is a one-stop clinical trial with three groups that was conducted in 2015-2016 to determine the effect of two methods of acupressure and ice massage on the Hugo point on the severity of postoperative appendectomy pain. For this purpose, firstly, researchers (female and male researcher) received the necessary training on the determination of points of practice of acupressure under the supervision of a specialist in traditional Chinese medicine. After confirming the skills of the researchers by the specialist, 90 patients after appendectomy surgery were randomly allocated to three groups of acupressure, ice massage and control. The sample size was calculated using $G$ * Power software and the number of samples required for the research with $95 \%$ confidence level and $80 \%$ test capability was considered as 30 subjects per group. Willingness to participate in the study, open appendectomy surgery, general anesthetic surgery, no known cognitive or psychological disorder, lack of diabetes, patients with anesthesia risks 1 and 2, no history of addiction and drug use, not having skin or scalp sensitivity at the LI4 point and having no history of acupressure and ice massage were the main inclusion criteria. Before the intervention, demographic and disease characteristics of all three units were registered in the relevant form. In this study, a 10-degree standardized visual analog scale was used to measure pain (11). The method of doing research was like the following; after determining the appendectomy specimens based on the criteria for entering the eligible patients and giving necessary explanations on how to conduct the research and the probability of being placed in the acupressure group, ice massage and or control and obtaining informed consent, the severity of pain was measured and recorded before the intervention. It should be noted that female and male researchers were used to observe the ethical issues of acupressure for female patients. In the acupressure group, researcher pressed the LI4 with his thumb clockwise for 5 minutes; then, he/she applied the same pressure on the opposite side for 5 minutes; the same process was conducted counterclockwise and this stage lasted about 20 minutes. In the ice massage group, the LI4 was massaged with a bag of ice (crushed ice at $3 \mathrm{~cm}$ in 3 $\mathrm{cm}$ ) for 20 minutes. The ice bag was replaced every ten minutes due to reduced efficacy. The intervention was conducted with researchers of the same sex on the test groups. The severity of pain was recorded before, immediately and one hour after the intervention in the three groups. All computations were performed using SPSS 20 and descriptive statistics, including Chi-square test, Fisher's exact test, ANOVA with repeated measures, One-way analysis of variance. This study was registered with the Ministry of Health's Clinical Trials (IRCT20170921036302N2). The significance level of statistical tests were considered 0.05 .

\section{Findings}

90 samples were examined in the study. The findings of Table 1 and 2 showed that there were no significant differences between the three groups regarding age, weight, body mass index and surgical history. The three groups were homogeneous before intervention.

The findings of Table 3 showed that there was no significant difference between the three groups in terms of pain before the intervention. There was a significant difference between the three groups in terms of pain immediately after intervention and one hour after intervention. Also, the results showed that acupressure and ice massage reduced the pain intensity of patients after appendectomy surgery. The results of Table 4 showed that there was no significant relationship between age, weight and BMI with pain before, immediately after and one hour after appendectomy. 
Sedighe Khalili-Shomia et.al., Effect of Acupressure and ice massage on post appendectomy pain

Table 1. Comparison of qualitative demographic characteristics and information of patients

\begin{tabular}{|c|c|c|c|c|}
\hline Group & Control group & Ice massage group & Acupressure group & \\
\hline Variable & Mean \pm SD & Mean \pm SD & Mean \pm SD & Test result \\
\hline Age (years & $24.96 \pm 7.65$ & $23.90 \pm 6.79$ & $26.70 \pm 9.94$ & $\mathrm{P}=0.412$ \\
\hline Weight & $64.28 \pm 10.98$ & $63.30 \pm 10.61$ & $60.30 \pm 11.70$ & $\mathrm{P}=0.782$ \\
\hline BMI & $21.62 \pm 1.73$ & $22.16 \pm 1.62$ & $21.95 \pm 1.64$ & $\mathrm{P}=0.501$ \\
\hline
\end{tabular}

Table 2. Comparison of quantitative and demographic characteristics of the samples

\begin{tabular}{|l|l|l|l|l|l|}
\hline Variable & \multicolumn{2}{|l|}{ Acupressure group } & Ice massage group & Control group & Test result \\
\hline \multicolumn{2}{|l|}{} & Frequency (percent) & Frequency (percent) & Frequency (percent) & $\begin{array}{l}\mathrm{X}^{2}=0.937 \\
\mathrm{P}=0.649\end{array}$ \\
\hline $\begin{array}{l}\text { History of } \\
\text { surgery }\end{array}$ & Yes & $7(25)$ & $7.36(11)$ & $9(30)$ & \\
\cline { 2 - 6 } & No & $21(75)$ & $19(36.6)$ & $21(70)$ & \\
\hline
\end{tabular}

Table 3. Comparison of the mean pain intensity of the samples before intervention, immediately and one hour after intervention in three groups of acupressure, ice massage and control

\begin{tabular}{|c|c|c|c|c|c|c|c|}
\hline \multirow[t]{2}{*}{ Group } & \multicolumn{2}{|c|}{ Before intervention } & \multicolumn{2}{|c|}{$\begin{array}{c}\text { One hour after } \\
\text { intervention }\end{array}$} & \multicolumn{2}{|c|}{$\begin{array}{c}\text { Immediately after } \\
\text { intervention }\end{array}$} & \multirow[t]{2}{*}{$\begin{array}{l}\text { Friedman } \\
\text { test result }\end{array}$} \\
\hline & Frequency & Mean \pm SD & Frequency & Mean \pm SD & Frequency & Mean \pm SD & \\
\hline Acupresure & 28 & $5.78 \pm 0.83$ & 28 & $5.42 \pm 0.92$ & 28 & $4.64 \pm 0.69$ & $\begin{array}{l}X^{2}=33.02 \\
9 \\
D f=2 \\
P=0.000\end{array}$ \\
\hline $\begin{array}{l}\text { Ice } \\
\text { massage }\end{array}$ & 30 & $5.63 \pm 1.24$ & 30 & $4.70 \pm 0.87$ & 30 & $3.60 \pm 0.77$ & $\begin{array}{l}X^{2}=55.05 \\
2 \\
D f=2 \\
P=0.000\end{array}$ \\
\hline Control & 30 & $5.66 \pm 0.71$ & 30 & $6.56 \pm 0.81$ & 30 & $6.0 .6 \pm 0.86$ & $\begin{array}{l}\mathrm{X}^{2}=36.31 \\
7 \\
\mathrm{Df}=2 \\
\mathrm{P}=0.000\end{array}$ \\
\hline $\begin{array}{l}\text { Kruskal } \\
\text { Wallis Test }\end{array}$ & \multicolumn{2}{|l|}{$\mathrm{P}=0.616$} & \multicolumn{2}{|l|}{$\mathrm{P}=0.00$} & \multicolumn{2}{|l|}{$\mathrm{P}=0.00$} & \\
\hline
\end{tabular}

Table 4: The Relationship between demographic variables with pain before, immediately after and one hour after intervention

\begin{tabular}{|c|c|c|c|}
\hline Variable & Before intervention & $\begin{array}{c}\text { Immediately after } \\
\text { intervention }\end{array}$ & $\begin{array}{c}\text { One hour after } \\
\text { intervention }\end{array}$ \\
\hline Age & $\mathrm{P}=0.998$ & $\mathrm{P}=0.561$ & $\mathrm{P}=0.551$ \\
\hline Weight & $\mathrm{P}=0.307$ & $\mathrm{P}=0.239$ & $\mathrm{P}=0.122$ \\
\hline BMI & $\mathrm{P}=0.123$ & $\mathrm{P}=0.858$ & $\mathrm{P}=0.385$ \\
\hline
\end{tabular}

\section{Discussion}

The results of the study showed that ice massage at Hugo point reduced the pain of patients after appendectomy, which is consistent with the results of Safdari et al. (15). Also, ....et al study, there was no significant difference between the severity and duration of pain before and after the intervention in the control group, but the mean and severity of pain in the acupressure and ice massage group at spatial point 6 decreased significantly after the intervention (16). Arab et al study also found that lidocaine $2 \%$ and ice mosaic at the Hugo point reduce pain caused by intra-arterial fistula. All three groups were homogeneous in terms of age, sex, education, history of surgery and BMI. There was no statistically significant association between these variables and the results of other studies. There was no significant relationship between age and sex $(17,11)$......et al study showed that ice massage at the Hugo point reduces pain in the acute lipid phase, although it does not significantly reduce the length of labor time (18). The results of this study showed that acupressure at the Hugo point reduced the pain intensity of appendectomy surgery. However, the comparison of the average pain intensity in different minutes showed that there was no significant relationship between pain in the acupressure group before and 
immediately after the intervention. The results Mohammad Pour et al study showed that acupressure exercises in the ear reduced the pain of patients undergoing appendectomy surgery 30 minutes after intervention, but there was no significant difference between acupressure group immediately and 15 minutes after intervention. The results of the research by Raftoin et al. showed that acupressure at SP6 points decreased the pain during birth of the newborns in comparison with the control group and the touch group (11). Several factors affecte the pain of the surgery, including individual differences regarding the severity of pain, cultural and social factors, and psychological factors; these factors affect the expression of pain, which is one of the limitations of this study. Also, because pain was a mental finding and self-reporting was a way of calculating pain, this could affect the outcome of the research. Based on the results of this study, it is suggested that the effect of different acupressure methods on the severity of pain before various surgeries and with a larger sample size should be investigated.

\section{Conclusion}

According to present results, it can be concluded that acupressure and ice massage can reduce the pain of patients after appendectomy surgery, which can be easily performed by the individual and does not require special equipment. Therefore, the use of acupressure and ice massage is recommended in patients with appendectomy.

\section{References}

1. Tadayon-Far M,Amadani M,Khosrowgerdi H,Tajabadi A,Tabrayi U. Camparison of the analgesic efficacy of diclofenac and morphine on pain appendectomy patients. Journal of Sabzevar University of Medical Sciences. 2014; 21(3); 379-385

2. Tadayon-Far M, Khorsand-vakil-zade A, Baghani S, Rakhshani M, Asadi M. The effect of reflexology massage on postoperative appendectomy pain. Journal of Sabzevar University Medical Sciences. 2014; 20 (5);696-705

3. Asadi F, Ebrahimi H, Mazlum R, Jangjou AMSN. The effect of early ambulation on nausea in patient undergoing appendectomy. Jornal of Evidence Based Care. 2013;3(6);49-58

4. Poorsheykhian M, Emami-Sigaroodi AH, Kazamnejad E, Raoof M. Incidence of post general anesthesia complication in recovery room. Juornal of Gilan University Medical Sciences. 2012;21(82);8-14

5. Adib-Hajibaghery M, Etri M, Hoseinian M. The effect of acupressure on the pericardium 6 point on pain,nausea and vomiting after appendectomy. Compelementry medicine. 2012;2;47-58

6. Kavian-nejad R, Tayyebi Arasteh M, Kohan M, Moradi M, Alitalab J, Amani S. Effect of methocarbamol on postoperative pain following cholecystectomy. Journal of Gorgan University
Medical Sciences. 2012; 14(3);46-51

7. Safae MD, Safi S. Evaluation of Effect of Ondansetron on Nausea and Vomiting after Elective Cholecystectomy Surgery in Women Older than 40 Years. Journal of Isfahan Medical School. 2011; 29 (149); 1021 1027.

8. Aypotter P, Angriffin P, Aystokert P, Am.hal o. Potter and Perry's Fundamentals of Nursing. 8 ed. Jameenegar-Salemi. 2013; 595-606

9. Zargarzadeh M, Memarian R. Assesing barriers for using of complementary medicine in relieving pain in patients by nurses.Quarterly Journal of Nursing Management. 2013;1(4);45-53.

10. Mohammadpour A, Basiri Moghaddam M, Davarinia Motlagh Quchan A, Mojtabavi J. Effect of ear acupressure on severity of pain in appendectomy candidate patients before surgery. Journal of Sabzevar University of Medical Sciences. 2018; 24(5); 237-332.

11. Mafetoni RR, Shimo AKK. The effects of acupressure on labor pains during child birth: randomized clinical trial. Revista Latino-Americana de Enfermagem. $2016 ; 24 ; 2738$.

12. Mohammadpour A, Basiri Moghaddam M, Davarinia Motlagh Quchan A, Mojtabavi J.Effect of Ear Acupressure on Anxiety and Severity of Nausea in Patients Candidate for Appendectomy: A Randomized Clinical Trial. Qom University of Medical Science. 2016; 10(7); 1-9.

13. Pouraboli B, Abazari F, Rostami M, Jahani Y. Comparison the effect of two methods of acupressure and massage with ice on Huko point on pain intensity during IV insertion in pediatrics with thalassemia. Iranian Journal of Pediatric Nursing. 2015; 2(2); 2027.

14. Bastani F, Sobhani M, Bozorgnejad M, Shamsikhani $\mathrm{S}$, Haghani H. Effect of acupuncture on severity of pain in women with multiple sclerosis (MS). Complementary medicine. 2012; 14(1); 75-84.

15. Safdari Dehcheshmeh F, Delaram M, Salehian T, Moradi M T, Rahimi Madiseh M, Aliakbari F. Relief of labor pain by ice massage of the hand. Zahedan Journal of Research in Medical Sciences. 2009; 11 (1); 23-30.

16. Rakhshekhorshid M, Foadoddini M, Saadatjoo SA. Comparison between the effects of applying massage and ice massage to SP6(SPLEEN6) point on severity and length of primary dysmenorrhea . Journal of Birjand University. 2013; 20 (1); 11-19.

17. Arab V, Bagheri-Nesami M, Mousavinasab SN, Espahbodi F, Pouresmail Z. Comparison of the Effects of Hegu Point Ice Massage and 2\% Lidocaine Gel on Arteriovenous Fistula Puncture-Related Pain in Hemodialysis Patients. A Randomized Controlled Trial. Journal of Caring Sciences. 2017; 6(2); 141151.

18. Hafize Ozturk Can, Aynur Saruhan. Evaluation of the effects of ice massage applied to large intestine 4 (hegu) on postpartum pain during the active phase of labor. Iranian Journal of Nursing and Midwifery Research. Jan-Feb 2015; 20(1); 129-138. 